\title{
Cavernous Angioleiomyoma
}

National Cancer Institute

\section{Source}

National Cancer Institute. Cavernous Angioleiomyoma. NCI Thesaurus. Code C49115.

A morphologic variant of angioleiomyoma characterized by the presence of markedly dilated vascular channels. 